\title{
Urinary tract infections and bladder management over the first year after discharge from inpatient rehabilitation
}

\author{
Michael D. Stillman ${ }^{1,2,5} \cdot$ Jeanne M. Hoffman ${ }^{1}$ Jason K. Barber ${ }^{3} \cdot$ Steve R. Williams ${ }^{1,5} \cdot$ Stephen P. Burns ${ }^{1,4}$
}

Received: 14 August 2018 / Revised: 24 September 2018 / Accepted: 28 September 2018

(c) International Spinal Cord Society 2018

\begin{abstract}
Study Design Secondary analysis of data from a prospective clinical trial of telephone counseling.

Objectives To describe changes in bladder management and development of bladder-related complications in the first year after discharge from inpatient spinal cord injury (SCI) rehabilitation. To determine whether urinary tract infection (UTI) is associated with bladder management technique or severity of SCI during this time period.

Setting One SCI Model System center.

Methods Post hoc analysis of bladder-specific responses to a phone intervention meant to reduce secondary complications of paralysis in adults $(n=169)$ over the first year after discharge from initial inpatient rehabilitation (IR).

Results Bladder management was associated with injury level during and immediately after inpatient rehabilitation, and with American Spinal Injury Association (ASIA) Impairment Scale (AIS) score over the entire year. During one year of followup, $19 \%$ of patients changed bladder management techniques. Among participants performing intermittent catheterization (IC), $20 \%$ had urinary incontinence weekly or more frequently. The cumulative incidence of UTI was $71 \%$ by the end of the study, and between 27 and $46 \%$ of subjects reported UTIs during each 3-month period. Subjects with spontaneous voiding reported significantly fewer UTIs than those using IC or indwelling catheterization (IDC), but there was no significant difference in UTIs between IC and IDC.

Conclusion During the first year following discharge, approximately one in five patients changed the bladder management technique and urinary incontinence occurred in a substantial proportion of those performing IC. These findings suggest a need for more frequent monitoring of bladder changes and complications over the first year after IR.
\end{abstract}

Michael D. Stillman

michael.stillman@jefferson.edu

$\triangle$ Steve R. Williams

Steve.r.williams@jefferson.edu

1 Department of Rehabilitation Medicine, University of Washington School of Medicine, Seattle, WA, USA

2 Department of Internal Medicine, University of Washington School of Medicine, Seattle, WA, USA

3 Department of Neurological Surgery, University of Washington School of Medicine, Seattle, WA, USA

4 Spinal Cord Injury Service, Veterans Administration Hospital Puget Sound Health Care System, Seattle, WA, USA

5 Present address: Sidney Kimmel Medical College, Thomas Jefferson University, Philadelphia, PA, USA

\section{Introduction}

The literature addressing management and complications of neurogenic bladder in chronic spinal cord injury (SCI) is extensive. It is known that people with SCI use mechanical, catheter-based, surgical, and pharmacological strategies for bladder emptying [1-3], that patients' bladder management methods may change over the course of an injury [4, 5], and that urinary tract infections (UTIs) are a significant problem in chronic SCI $[6,7]$, with as many as $56.5 \%$ of individuals with injuries developing them on an annual basis [8]. Studies have demonstrated that bladder dysfunction is the most common cause of hospitalization among people with chronic SCI [9] and that urinary tract disease and urosepsis cause considerable mortality [10,11]. Multiple factors must be considered in developing optimal plans for bladder management, including potential risks and benefits of specific methods and patients' anatomy, hand and cognitive 
function, detrusor pressures, fluid intake and requirements, and care giver availability [3].

Fewer data are available about the management and complications of neurogenic bladder soon after initial hospital discharge. While some studies indicate that UTIs and bladder dysfunction have no more than a mild impact on injured individuals' lifestyles and independence [12, 13], others indicate that both bladder management and infection are of significant concern $[14,15]$. UTI during inpatient rehabilitation (IR) [16] and use of indwelling catheters (IDC) [17] have been correlated with early rehospitalization. Intermittent catheterization (IC) program use drops within the first year after discharge from IR [5, 11]. The incidence of UTI during the first year of injury is between 47 and 62\% [14, 15], and genitourinary complications (including UTI) are the most common cause of emergency room visits and re-hospitalizations in the 12 months following discharge from acute rehabilitation [18]. While urinary infections account for approximately $50 \%$ of bacteremic episodes among people living in longterm care facilities [19], they cause between $65 \%$ and $75 \%$ of cases in individuals with SCI [20,21].

In this paper we sought to determine the frequency of self-reported UTI, incontinence, and use of bladder management techniques at multiple time points across the first year following discharge from acute rehabilitation. We further sought to assess potential associations between injury severity, bladder emptying strategy, and risk of UTI and incontinence. Our goal was to better illuminate bladderspecific challenges faced by individuals who have recently sustained SCI and to gather data that will help patients and clinicians develop optimal bladder management plans.

\section{Methods}

Data were gathered from 169 adults with traumatic SCI who completed a randomized controlled trial that compared telephone counseling interventions with usual care across the first year following discharge from IR [22]. Full inclusion criteria are those of the National Institute on Disability, Independent Living, and Rehabilitation Research (NIDILRR) funded Spinal Cord Injury Model System [23]. Briefly, all participants were 18 years of age or older and had been admitted to and completed IR within one year of injury. Exclusion criteria included lack of a telephone, being a non-English speaker, and exhibiting active psychosis. The randomized controlled trial showed no improvement in primary outcomes of health-care utilization in the telephone intervention versus the control group. Similarly, there were no statistically significant differences between intervention and control groups with respect to the primary outcomes examined in this study (UTIs and bladder incontinence). For those reasons, we combined data from the intervention and control groups for all analyses in this study.

Bladder management technique during IR and at time of discharge was determined by an inpatient attending physiatrist in consultation with urologists, as needed, and following principles in clinical practice guidelines [3]. In general, these physicians recommended IC when the patient had sufficient hand function to use this method independently or had a care giver who was available to learn the technique during his/her inpatient stay. Use of spontaneous voiding was limited to voluntary voiding, with no attempt to use reflex voiding as a method of bladder management. This was due to two factors: (a) IR lengths of stay have decreased, and there can be significant change in bladder function early in injury; and (b) patients cared for at our center return to home across a five state region, and use of IC or IDC can limit incontinence, prevent development of high intravesicular pressures, and help limit infection from incomplete emptying, all of which can occur with reflex voiding. Following discharge, changes to the bladder management technique were made by staff from the center's outpatient rehabilitation medical clinic, by the patient's primary care provider, or by specialist physicians unaffiliated with the center.

Eighty percent of eligible patients admitted between the years 2007 and 2010 agreed to participate and were followed prospectively via structured phone interviews at 3,6, 9 , and 12 months after discharge. Research staff successfully obtained phone interview data on between 79 and $88 \%$ of subjects during each of the telephone calls at 3-month intervals. Participants were asked whether they had developed any SCI-related complications since last having been contacted, and the phone interviews contained questions about self-reported UTIs, urinary incontinence, and bladder management strategies utilized. UTIs were assessed by asking participants whether they had experienced a UTI during the prior 3 months, and if so, how many. While formal criteria for infection identification were not assessed, subject responses represented "real world" medical care. Participants were asked how they were managing their bladder at the time of each interview as well as how frequently they experience bladder incontinence.

Incidence of UTI at each assessment refers to the proportion of new cases, and was thus calculated as the proportion of previously UTI-free subjects who developed an infection during the previous 3 months. Cumulative incidence was also calculated as a sample proportion, but since these naive estimates are usually biased by missing data we have also provided Kaplan-Meier estimates of cumulative incidence (CI) calculated as the cumulative product of the non-UTI incidences through time-of-assessment and subtracting from one. Differences in UTI rates among various management strategies at each assessment were tested 
statistically using Fisher's exact test and post hoc pairwise testing [24]. Additionally, multivariate logistic regression was used to adjust these analyses for level of injury. All study interventions were approved by the University of Washington Institutional Review Board. We certify that all applicable institutional and governmental regulations concerning the ethical use of human volunteers were following during the course of this research.

\section{Results}

Participants' mean age was 41 years, $79 \%$ were males, and $83 \%$ identified as White. Thirty-four percent had American Spinal Injury Association (ASIA) Impairment Scale (AIS) grade A-C cervical injuries, $28 \%$ had AIS A-C injuries below T1, and 38\% had AIS D injuries. Eighty percent of subjects had been initially discharged to private homes, and the majority of the remainder $(18 \%)$ were discharged to nursing homes or skilled nursing facilities. Although the regional SCI center serves a large geographic area, only $32 \%$ of participants lived more than 100 miles from the center, and $43 \%$ lived within 30 miles. The majority $(81 \%)$ resided in metropolitan locations when initially discharged.

At time of discharge from IR, $44 \%$ of participants were using IDC, $21 \%$ were using IC, and $33 \%$ were voiding spontaneously. At 12 month follow-up, 29\% were using IDC, $27 \%$ were using IC, and $43 \%$ were voiding spontaneously (Table 1). None of these changes reached statistical significance. Bladder management strategies during the first

Table 1 Sample descriptives

\begin{tabular}{|c|c|c|c|c|c|}
\hline & Baseline & 3 months & 6 months & 9 months & 12 months \\
\hline \multicolumn{6}{|l|}{ Assessed for follow-up at time point } \\
\hline Yes & $169(100 \%)$ & $136(80 \%)$ & $133(79 \%)$ & $138(82 \%)$ & $149(88 \%)$ \\
\hline No & $0(0 \%)$ & $33(20 \%)$ & $36(21 \%)$ & $31(18 \%)$ & $20(12 \%)$ \\
\hline \multicolumn{6}{|l|}{ Bladder management } \\
\hline $\begin{array}{l}\text { Foley/Suprapubic/Indwelling } \\
\text { catheter }\end{array}$ & $74(44 \%)$ & $47(35 \%)$ & $43(32 \%)$ & $47(34 \%)$ & $42(29 \%)$ \\
\hline Intermittent catheterization & $35(21 \%)$ & $31(23 \%)$ & $36(27 \%)$ & $38(28 \%)$ & $39(27 \%)$ \\
\hline $\begin{array}{l}\text { Crede (manual expression of } \\
\text { urine) }\end{array}$ & $0(0 \%)$ & $0(0 \%)$ & $0(0 \%)$ & $0(0 \%)$ & $0(0 \%)$ \\
\hline Spontaneous & $55(33 \%)$ & $58(43 \%)$ & $52(39 \%)$ & $52(38 \%)$ & $63(43 \%)$ \\
\hline Other & $4(2 \%)$ & $0(0 \%)$ & $2(2 \%)$ & $1(1 \%)$ & $3(2 \%)$ \\
\hline Unknown & 1 & 0 & 0 & 0 & 2 \\
\hline \multicolumn{6}{|l|}{ Bladder incontinence frequency } \\
\hline No incontinence & $36(78 \%)$ & $44(62 \%)$ & $47(57 \%)$ & $53(58 \%)$ & $63(59 \%)$ \\
\hline Only occasionally & $5(11 \%)$ & $14(20 \%)$ & $13(16 \%)$ & $14(15 \%)$ & $13(12 \%)$ \\
\hline At least once per month & $1(2 \%)$ & $3(4 \%)$ & $4(5 \%)$ & $7(8 \%)$ & $6(6 \%)$ \\
\hline Every other week & $0(0 \%)$ & $0(0 \%)$ & $3(4 \%)$ & $3(3 \%)$ & $3(3 \%)$ \\
\hline Every week & $1(2 \%)$ & $2(3 \%)$ & $7(9 \%)$ & $2(2 \%)$ & $13(12 \%)$ \\
\hline Every day & $1(2 \%)$ & $3(4 \%)$ & $5(6 \%)$ & $7(8 \%)$ & $4(4 \%)$ \\
\hline Twice or more per day & $2(4 \%)$ & $5(7 \%)$ & $3(4 \%)$ & $5(5 \%)$ & $4(4 \%)$ \\
\hline $\begin{array}{l}\text { N/A—catheterized (option \#1 } \\
\text { above) }\end{array}$ & 74 & 47 & 43 & 47 & 42 \\
\hline Unknown & 49 & 18 & 8 & 0 & 1 \\
\hline \multicolumn{6}{|c|}{ Bladder incontinence by management technique ( $\%$ incontinent $\geq 1$ per month) } \\
\hline Intermittent catheterization & $4 / 23(17 \%)$ & $9 / 25(36 \%)$ & $13 / 31(42 \%)$ & $16 / 38(42 \%)$ & $17 / 39(44 \%)$ \\
\hline Spontaneous & $1 / 23(4 \%)$ & $4 / 46(9 \%)$ & $8 / 50(16 \%)$ & $8 / 52(15 \%)$ & $10 / 62(16 \%)$ \\
\hline Other & $0 / 0$ & $0 / 0$ & $1 / 1(100 \%)$ & $0 / 1(0 \%)$ & $2 / 3(67 \%)$ \\
\hline $\begin{array}{l}\text { N/A-Catheterized (option \#1 } \\
\text { above) }\end{array}$ & 74 & 47 & 43 & 47 & 42 \\
\hline Unknown & 49 & 18 & 8 & 0 & 3 \\
\hline \multicolumn{6}{|l|}{ Additional complications } \\
\hline $\begin{array}{l}\text { Urologic complications other } \\
\text { than UTI and incontinence }\end{array}$ & $1(1 \%)$ & $11(8 \%)$ & $15(11 \%)$ & $19(14 \%)$ & $15(10 \%)$ \\
\hline
\end{tabular}

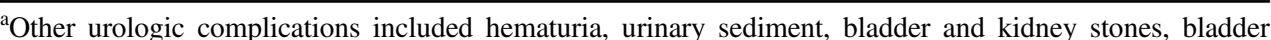
spasms, urinary retention, traumatic hypospadias 
Table 2 Associations of urinary tract infection and bladder management strategy with severity of injury

\begin{tabular}{|c|c|c|c|c|c|}
\hline & Baseline & 3 months & 6 months & 9 months & 12 months \\
\hline \multicolumn{6}{|l|}{ Rates of urinary tract infection (UTI) } \\
\hline Prevalence & $42 \%(71 / 169)$ & $46 \%(62 / 135)$ & $34 \%(45 / 132)$ & $30 \%(41 / 138)$ & $27 \%(40 / 147)$ \\
\hline Incidence $^{1}$ & $42 \%(71 / 169)$ & $33 \%(27 / 81)$ & $9 \%(5 / 54)$ & $6 \%(3 / 51)$ & $11 \%(6 / 53)$ \\
\hline Cumulative incidence $^{2}$ & $42 \%(71 / 169)$ & $64 \%(98 / 152)$ & $68 \%(103 / 152)$ & $69 \%(106 / 154)$ & $70 \%(112 / 159)$ \\
\hline Cumulative incidence (Kaplan-Meier) ${ }^{3}$ & $42 \%$ & $61 \%$ & $65 \%$ & $67 \%$ & $71 \%$ \\
\hline \multicolumn{6}{|l|}{ Rates of indwelling catheterization by injury level } \\
\hline AIS A-B/C1-C4 & $28 / 29(97 \%)$ & $23 / 24(96 \%)$ & $22 / 24(92 \%)$ & $24 / 25(96 \%)$ & $24 / 26(92 \%)$ \\
\hline AIS $\mathrm{C} / \mathrm{C} 1-\mathrm{C} 4$ & $4 / 5(80 \%)$ & $2 / 3(67 \%)$ & $3 / 4(75 \%)$ & $1 / 4(25 \%)$ & $2 / 5(40 \%)$ \\
\hline AIS A-B/C5-C8 & $14 / 19(74 \%)$ & $11 / 17(65 \%)$ & $7 / 15(47 \%)$ & $9 / 17(53 \%)$ & $9 / 18(50 \%)$ \\
\hline AIS C/C5-C8 & $2 / 3(67 \%)$ & $0 / 3(0 \%)$ & $0 / 3(0 \%)$ & $0 / 3(0 \%)$ & $0 / 3(0 \%)$ \\
\hline AIS A-B/paraplegia & $14 / 35(40 \%)$ & $6 / 24(25 \%)$ & $7 / 29(24 \%)$ & $8 / 31(26 \%)$ & $4 / 28(14 \%)$ \\
\hline AIS C/paraplegia & $4 / 11(36 \%)$ & $2 / 10(20 \%)$ & $2 / 10(20 \%)$ & $2 / 10(20 \%)$ & $1 / 11(9 \%)$ \\
\hline AIS D & $7 / 63(11 \%)$ & $2 / 53(4 \%)$ & $2 / 46(4 \%)$ & $3 / 46(7 \%)$ & $2 / 53(4 \%)$ \\
\hline Unknown & $1 / 3(33 \%)$ & $1 / 2(50 \%)$ & $0 / 2(0 \%)$ & $0 / 2(0 \%)$ & $0 / 3(0 \%)$ \\
\hline Proportion of subjects with indwelling catheter in categories $5 / 6 / 7$ reporting UTI & $44 \%(11 / 25)$ & $60 \%(6 / 10)$ & $55 \%(6 / 11)$ & $62 \%(8 / 13)$ & $83 \%(5 / 6,1$ unk. $)$ \\
\hline \multicolumn{6}{|l|}{ Rates of UTI by AIS ievel } \\
\hline AIS A & $28 / 54(52 \%)$ & $30 / 40(75 \%)$ & $24 / 42(57 \%)$ & $22 / 47(47 \%)$ & $19 / 45(42 \%)$ \\
\hline AIS B & $16 / 29(55 \%)$ & $18 / 25(72 \%)$ & $10 / 25(40 \%)$ & $11 / 26(42 \%)$ & $7 / 27(26 \%)$ \\
\hline AIS C & $9 / 20(45 \%)$ & $8 / 15(53 \%)$ & $6 / 17(35 \%)$ & $5 / 17(29 \%)$ & $11 / 20(55 \%)$ \\
\hline AIS D & $18 / 63(29 \%)$ & $6 / 53(11 \%)$ & $5 / 46(11 \%)$ & $3 / 46(7 \%)$ & $3 / 52(6 \%)$ \\
\hline Unknown & $0 / 3(0 \%)$ & $0 / 2(0 \%)$ & $0 / 2(0 \%)$ & $0 / 2(0 \%)$ & $0 / 3(0 \%)$ \\
\hline AIS A-B & $44 / 83(53 \%)$ & $48 / 65(74 \%)$ & $34 / 67(51 \%)$ & $33 / 73(45 \%)$ & $26 / 72(36 \%)$ \\
\hline AIS C-D & $27 / 83(33 \%)$ & $14 / 68(21 \%)$ & $11 / 63(17 \%)$ & $8 / 63(13 \%)$ & $14 / 72(19 \%)$ \\
\hline Significance & 0.012 & $<0.001$ & $<0.001$ & $<0.001$ & 0.040 \\
\hline \multicolumn{6}{|l|}{ Rates of UTI by injury level } \\
\hline Paraplegia & $18 / 53(34 \%)$ & $14 / 44(32 \%)$ & $15 / 47(32 \%)$ & $14 / 49(29 \%)$ & $13 / 48(27 \%)$ \\
\hline Cervical & $50 / 106(47 \%)$ & $48 / 86(56 \%)$ & $30 / 79(38 \%)$ & $27 / 83(33 \%)$ & $26 / 89(29 \%)$ \\
\hline Unknown & $3 / 10(30 \%)$ & $0 / 5(0 \%)$ & $0 / 6(0 \%)$ & $0 / 6(0 \%)$ & $1 / 10(10 \%)$ \\
\hline Significance & 0.128 & 0.015 & 0.566 & 0.700 & 0.845 \\
\hline \multicolumn{6}{|l|}{ Rates of UTI by injury severity } \\
\hline AIS A-B/C1-C4 & $21 / 29(72 \%)$ & $21 / 24(88 \%)$ & $13 / 24(54 \%)$ & $14 / 25(56 \%)$ & $10 / 25(40 \%)$ \\
\hline AIS C/C1-C4 & $2 / 5(40 \%)$ & $2 / 3(67 \%)$ & $3 / 4(75 \%)$ & $1 / 4(25 \%)$ & $3 / 5(60 \%)$ \\
\hline AIS A-B/C5-C8 & $11 / 19(58 \%)$ & $15 / 17(88 \%)$ & $9 / 15(60 \%)$ & $7 / 17(41 \%)$ & $7 / 18(39 \%)$ \\
\hline AIS C/C5-C8 & $1 / 3(33 \%)$ & $2 / 3(67 \%)$ & $1 / 3(33 \%)$ & $2 / 3(67 \%)$ & $2 / 3(67 \%)$ \\
\hline AIS A-B/paraplegia & $12 / 35(34 \%)$ & $12 / 24(50 \%)$ & $12 / 28(43 \%)$ & $12 / 31(39 \%)$ & $9 / 29(31 \%)$ \\
\hline AIS C/paraplegia & $6 / 12(50 \%)$ & $4 / 9(44 \%)$ & $2 / 10(20 \%)$ & $2 / 10(20 \%)$ & $6 / 12(50 \%)$ \\
\hline AIS D & $18 / 63(29 \%)$ & $6 / 53(11 \%)$ & $5 / 46(11 \%)$ & $3 / 46(7 \%)$ & $3 / 52(6 \%)$ \\
\hline Unknown & $0 / 3(0 \%)$ & $0 / 2(0 \%)$ & $0 / 2(0 \%)$ & $0 / 2(0 \%)$ & $0 / 3(0 \%)$ \\
\hline \multicolumn{6}{|l|}{ Prevalence of UTI by bladder management strategy } \\
\hline Foley/Suprapubic/Indwelling catheter & $42 / 74(57 \%)^{\mathbf{a}}$ & $38 / 47(81 \%)^{\mathbf{A}}$ & $26 / 43(60 \%)^{\mathbf{A}}$ & $26 / 47(55 \%)^{\mathbf{A}}$ & $19 / 40(48 \%)^{\mathbf{A}}$ \\
\hline Intermittent catheterization & $13 / 35(37 \%)$ & $19 / 31(61 \%)^{\mathbf{B}}$ & $16 / 35(46 \%)^{\mathbf{B}}$ & $13 / 38(34 \%)^{\mathbf{B}}$ & $12 / 39(31 \%)$ \\
\hline Crede (push on bladder) & - & - & - & - & - \\
\hline Spontaneous & $12 / 55(22 \%)^{\mathbf{a}}$ & $5 / 57(9 \%)^{\mathbf{A B}}$ & $3 / 52(6 \%)^{\mathbf{A B}}$ & $2 / 52(4 \%)^{\mathbf{A B}}$ & $6 / 63(10 \%)^{\mathbf{A}}$ \\
\hline Other & $3 / 4(75 \%)$ & - & $0 / 2(0 \%)$ & $0 / 1(0 \%)$ & $1 / 3(33 \%)$ \\
\hline Significance $^{4}$ & $<0.001$ & $<0.001$ & $<0.001$ & $<0.001$ & $<0.001$ \\
\hline Significance $^{5}$ & 0.005 & $<0.001$ & $<0.001$ & $<0.001$ & 0.003 \\
\hline Unknown & $1 / 1(100 \%)$ & - & - & - & $2 / 2(100 \%)$ \\
\hline
\end{tabular}

${ }^{1}$ Incidence estimates are based only on subjects with known status at the specified time point and who have no UTI reported at any prior assessments

${ }^{2}$ Cumulative incidence estimates will include subjects with unknown status at the specified time point provided a UTI had been previously reported

${ }^{3}$ The KM estimate is derived by taking the product of the non-UTI incidences through the specified time point, then subtracting from 1

${ }^{4}$ Statistical significance by Fisher's exact

${ }^{5}$ Statistical significance by logistic regression after adjusting for injury level

${ }^{\mathrm{a}, \mathrm{b}}$ Post hoc pairwise significance $<0.05 ;{ }^{\mathrm{A}, \mathrm{B}}$ Post hoc pairwise significance $<0.01$

year after discharge were associated with level and completeness of injury; over $90 \%$ of individuals with high cervical motor complete injuries but fewer than $26 \%$ of people with paraplegia and less than $8 \%$ of people with AIS D injuries utilized IDC (Table 2). Nineteen percent of subjects reported having changed their bladder management 
strategy during the follow-up period. Among participants not using IDC, between $14 \%$ and $20 \%$ reported bladder incontinence at least weekly. Forty-four percent of those performing IC experienced incontinence at least monthly at 1-year follow-up (Table 1).

Forty-two percent of subjects developed a UTI during IR, and CI rose to $71 \%$ by the end of the study (Table 2). While prevalence rates of infection were between $27 \%$ and $46 \%$ at each follow-up assessment, incidence of UTI-a measure of first-time infections among participants-was between $6 \%$ and $11 \%$ at the 6-, 9-, and 12-month interviews. Hence, most cases of UTI during the study period were recurrent. Of note, there were no differences in rates of UTI or other bladder complications between male and female subjects. During the first year after discharge, 3month prevalence rates of UTI were between $48 \%$ and $81 \%$ among individuals using IDC and between $31 \%$ and $61 \%$ among those using IC (Table 2). Differences in infection rates among all management strategies were significant at every follow-up $(p<0.001)$. Participants who voided spontaneously suffered fewer UTIs than those utilizing IDC at all post-baseline assessments $(p<0.01)$ and suffered fewer UTIs than those using IC at months 3,6 , and $9(p<$ $0.01)$. The relationship between UTI and bladder management method remained very strong at each follow-up, even after adjusting for injury level (Table 2).

Rates of UTI were associated with severity of SCI. Participants with motor complete injuries (AIS A and B) were significantly more likely to develop UTI both during and after IR than were those with motor incomplete (AIS C and D) injuries (Table 2). Subjects with tetraplegia were more likely than those with paraplegia to suffer UTIs during the first 3 months after discharge from IR, but the two cohorts' incidence rates equalized thereafter. Among the small cohort of participants with paraplegia or AIS D injuries who utilized IDC, rates of UTI varied between $44 \%$ and $83 \%$.

\section{Discussion}

To our knowledge, this is the first study to report on the risk of UTI among people with SCI during the first year after discharge from IR. It is also the first to attempt to determine if risk of UTI within that time period is associated with bladder management strategy or severity of injury and to characterize early utilization of bladder drainage techniques. At each time point, use of IDC was greatest among participants with $\mathrm{C} 1-\mathrm{C} 4$ AIS A-B injuries, intermediate for those with $\mathrm{C} 5-\mathrm{C} 8$ AIS A-B injuries, lower for those with AIS A-B paraplegia, and lowest for those with AIS D injuries. It seems, then, that clinicians at the study center were choosing bladder management methods based on patient factors, rather than attempting to apply the same bladder management method to all patients.

Contrary to some prior study findings [12, 13], this work indicates that genitourinary dysfunction is of significant concern for people with traumatic SCI recently discharged from IR. Nineteen percent reported having altered their bladder management strategy, and since not all patients received close follow-up, it is possible that the proportion who may have benefited from changing bladder management could be ever greater. While many of our subjects moved away from IDC, it is notable that studies of individuals with SCI of longer duration have described increased utilization of indwelling strategies [25, 26]. Perhaps the former trend is due to recovery of upper extremity function and independence soon after injury, while the latter reflects a need for convenience. It is additionally notable that among individuals not using IDC at 1 year follow-up, 20\% reported at least weekly incontinence during one or more of the quarterly interviews.

Our second important finding is that among our participants with recent traumatic SCI, the rate of UTI did not differ significantly between IDC and IC. Some authors have argued that IC is the optimal long-term bladder management method [27, 28], but recent recommendations are less declarative, and suggest that health-care providers consider a variety of patient-specific factors in determining the best course of treatment [3]. Those who were able to use spontaneous voiding for bladder management experienced the lowest rate of UTIs, which is consistent with prior studies showing lowest incidence of renal stones when this method can be used for bladder emptying [29]. Our findings' lack of significance may simply have been due to a relatively small sample size; it is notable that though not reaching significance, prevalence of UTI at each time point was between $14 \%$ and $21 \%$ lower for those employing intermittent versus indwelling strategies.

Third, we were surprised to find that individuals with tetraplegia - who may have diminished hand function and who were more likely to utilize indwelling drainage systems -were no more likely than those with paraplegia to report occurrence of UTIs. This could be a reflection of a relative small " $n$," and our assumption is that differences in infection rates would reach statistical significance in a larger study population. That participants with motor complete injuries reported more UTIs than those with motor incomplete injuries was, perhaps, expected, and underscores the need for care providers to be particularly vigilant in caring for people with AIS A and B SCI, especially soon after discharge from IR. Additionally, while only between 6 and 13 subjects with paraplegia or AIS D injuries utilized IC at each follow-up, they were at substantial risk for UTI. While recommendations about optimal bladder management are equivocal, these findings may sway clinicians to more 
strongly recommend IC to patients with adequate hand function and without anatomic limitations.

Finally, this study is the first to describe the risk of recurrent UTI in the first year after discharge from IR, and to demonstrate that people who develop UTIs soon after injury are at increased risk of future UTIs. Thietje et al. [30] found that septicemia not due to respiratory infection had caused $26 \%$ of mortality in a cohort of individuals with SCI, and in Rabadi et al.'s [10] analysis of 150 veterans with injuries, UTIs had caused $14 \%$ of deaths. Sixty-five to $76 \%$ of bacteremic episodes among people with chronic injuries are due to UTI [20, 21], and SCI Model System data suggest that genitourinary infections cause approximately $3 \%$ of deaths among individuals with injuries [31]. UTIs in the setting of SCI are a serious concern, and our data indicate a need for more effective infection prevention measures early after injury and for further work identifying who with SCI is at highest risk for repeated infections.

There are certainly opportunities to improve injured patients' bladder management in the first year following discharge from IR. As noted above, it is possible that more than one in five of our subjects may have benefited from change in bladder drainage strategy, and a good number suffered from frequent incontinence. Most physiatrists and some generalists are comfortable managing medications that facilitate bladder storage and transitioning patients with SCI to and between bladder management programs; these data support the need for input during the first year postdischarge by providers who can competently assess and manage neurogenic bladder. While the first year postdischarge is likely the period when bladder management strategies most frequently need modification, the optimal duration for close (more frequently than yearly) bladder management follow-up remains unknown. There is likely a role for patient education for self-identification of conditions warranting change in bladder management, as well as for patient initiation of requests for assistance in reducing incontinence frequency.

\section{Study limitations}

This study represents outcomes in patients discharged from a single center at which attending physicians tend not to recommend reflex voiding strategies or IC when it cannot be performed independently. Hence, our data may not be entirely applicable to individuals treated at other SCI centers. As UTIs were self-reported by participants and not by laboratory data, medical records, or accepted subjective and objective criteria of UTI in the setting of SCI, we cannot determine if treating clinicians correctly discriminated between UTI and asymptomatic bacteriuria, nor whether participants were accurate in reporting. However, our 3month assessment intervals increased the likelihood of accurate reporting, and our phone-based data collection strategy allowed us to include patients who lived at a distance and who were managed by providers not affiliated with our center. Further, our results reflect "real world" and community practice, where the majority of UTI care is managed by primary care providers who may not be familiar with nuances of managing UTI in individuals with neurogenic bladder. We did not record whether subjects with indwelling systems used urethral or suprapubic catheters, so cannot assess whether outcomes differed between these two management strategies, and the data we gleaned were far less specific and nuanced than those delineated in the International Spinal Cord Injury Data Sets [32], limiting our ability to compare our results with those of future studies. Including questions from the Lower Urinary Tract Autonomic Standard Assessment Form [33] would have further allowed us to compare our results to those of other researchers and to correlate need to empty the bladder and incontinence with UTI. Additionally, our data set was too small to meaningfully address incidence of a variety of individual non-UTI bladder complications, and patients using IDC were not asked whether they experienced urinary incontinence, which is known to be less common with indwelling systems but which may still occur. Finally, we are not able to determine from these data whether reported incontinence was due to infection. This being said, the high prevalence of frequent incontinence (at least weekly) makes it unlikely that most cases are due to UTI.

\section{Conclusions}

When assessed at multiple points during the first year postdischarge, UTIs and incontinence were highly prevalent and a substantial proportion of patients changed bladder management during this period of time. Clinicians should educate patients about these expected complications and anticipate these patterns of UTI when arranging for postdischarge medical care (including primary care) for individuals with new SCI.

Funding This work was supported by the Northwest Regional Spinal Cord Injury System funded by the National Institute on Disability, Independent Living, and Rehabilitation Research Grant numbers H133N110009 and 90SI2006.

\section{Compliance with ethical standards}

Conflict of interest The authors declare that they have no conflict of interest. 


\section{References}

1. Taweel WA, Seyam R. Neurogenic bladder in spinal cord injury patients. Res Rep Urol. 2015;7:85-99. https://doi.org/10.2147/ RRU.S29644

2. Burns AS, Rivas DA, Ditunno JF. The management of neurogenic bladder and sexual dysfunction after spinal cord injury. Spine (Phila Pa 1976). 2001;26(Suppl):S129-36.

3. Consortium for Spinal Cord Medicine. Bladder management for adults with spinal cord injury: a clinical practice guideline for health-care providers. J Spinal Cord Med. 2006;29:527-73.

4. McKinley WO, Jackson AB, Cardenas DD, DeVivo MJ. Longterm medical complications after traumatic spinal cord injury: a regional model systems analysis. Arch Phys Med Rehabil. 1999;80:1402-10. S0003999399000520 [pii].

5. Cameron AP, Wallner LP, Tate DG, Sarma AV, Rodriguez GM, Clemens JQ. Bladder management after spinal cord injury in the United States 1972 to 2005. J Urol. 2010;184:213-7. https://doi. org/10.1016/j.juro.2010.03.008

6. Charlifue SW, Weitzenkamp DA, Whiteneck GG. Longitudinal outcomes in spinal cord injury: aging, secondary conditions, and well-being. Arch Phys Med Rehabil. 1999;80:1429-34. S00039993(99)90254-X

7. New PW. Secondary conditions in a community sample of people with spinal cord damage. J Spinal Cord Med. 2016;39:665-70. https://doi.org/10.1080/10790268.2016.1138600

8. Noreau L, Proulx P, Gagnon L, Drolet M, Laramee MT. Secondary impairments after spinal cord injury: a population-based study. Am J Phys Med Rehabil. 2000;79:526-35.

9. Cardenas DD, Hoffman JM, Kirshblum S, McKinley W. Etiology and incidence of rehospitalization after traumatic spinal cord injury: a multicenter analysis. Arch Phys Med Rehabil. 2004;85:1757-63. S0003-9993(04)00387-9

10. Rabadi MH, Mayanna SK, Vincent AS. Predictors of mortality in veterans with traumatic spinal cord injury. Spinal Cord. 2013;51:784-8. https://doi.org/10.1038/sc.2013.77

11. National Spinal Cord Injury Statistical Center. 2015 annual statistical report for the spinal cord injury model systems public version. Birmingham, Alabama: University of Alabama at Birmingham. https://www.nscisc.uab.edu/reports.aspx. Accessed March 2017.

12. Kennedy P, Sherlock O, McClelland M, Short D, Royle J, Wilson C. A multi-centre study of the community needs of people with spinal cord injuries: The first 18 months. Spinal Cord. 2010;48:15-20. https://doi.org/10.1038/sc.2009.65

13. Dudley-Javoroski S, Shields RK. Assessment of physical function and secondary complications after complete spinal cord injury. Disabil Rehabil. 2006;28:103-10. PK81726335575216

14. Haisma JA, van der Woude LH, Stam HJ, et al. Complications following spinal cord injury: occurrence and risk factors in a longitudinal study during and after inpatient rehabilitation. J Rehabil Med. 2007;39:393-8. https://doi.org/10.2340/165019770067

15. Stillman MD, Barber J, Burns S, Williams S, Hoffman JM. Complications of spinal cord injury over the first year after discharge from inpatient rehabilitation. Arch Phys Med Rehabil. 2017;98:1800-5. S0003-9993(17)30013-8

16. DeJong $\mathrm{G}$, Tian $\mathrm{W}$, Hsieh $\mathrm{CH}$, et al. Rehospitalization in the first year of traumatic spinal cord injury after discharge from medical rehabilitation. Arch Phys Med Rehabil. 2013;94(Suppl):S87-97. https://doi.org/10.1016/j.apmr.2012.10.037

17. Eastwood EA, Hagglund KJ, Ragnarsson KT, Gordon WA, Marino RJ. Medical rehabilitation length of stay and outcomes for persons with traumatic spinal cord injury-1990-1997. Arch Phys Med Rehabil. 1999;80:1457-63. S0003-9993(99)90258-7

18. Skelton F, Hoffman JM, Reyes M, Burns SP. Examining healthcare utilization in the first year following spinal cord injury. $\mathrm{J}$ Spinal Cord Med. 2015;38:690-5. https://doi.org/10.1179/ 2045772314Y.0000000269

19. Hooton TM, Bradley SF, Cardenas DD, et al. Diagnosis, prevention, and treatment of catheter-associated urinary tract infection in adults: 2009 International clinical practice guidelines from the Infectious Diseases Society of America. Clin Infect Dis. 2010;50:625-63.

20. Evans CT, Hershow RC, Chin A, Foulis PR, Burns SP, Weaver FM. Bloodstream infections and setting of onset in persons with spinal cord injury and disorder. Spinal Cord. 2009;47:610-5. https://doi.org/10.1038/sc.2009.2

21. Waites KB, Canupp KC, Chen Y, DeVivo MJ, Moser SA. Bacteremia after spinal cord injury in initial versus subsequent hospitalizations. J Spinal Cord Med. 2001;24:96-100.

22. Mackelprang JL, Hoffman JM, Garbaccio C, Bombardier CH. Outcomes and lessons learned from a randomized controlled trial to reduce health care utilization during the first year after spinal cord injury rehabilitation: telephone counseling versus usual care. Arch Phys Med Rehabil. 2016;97:1793-1796.e1. https://doi.org/ 10.1016/j.apmr.2016.03.002

23. Chen Y, DeVivo MJ, Richards JS, SanAgustin TB. Spinal cord injury model systems: review of program and national database from 1970 to 2015. Arch Phys Med Rehabil. 2016;97:1797-804. https://doi.org/10.1016/j.apmr.2016.02.027

24. Zar J. Biostatistical analysis. 4th ed. New Jersey: Prentice Hall; 1999.

25. Savic G, Frankel HL, Jamous MA, Soni BM, Charlifue S. Longterm bladder and bowel management after spinal cord injury: a 20year longitudinal study. Spinal Cord. 2018;56:575-81. https://doi. org/10.1038/s41393-018-0072-4

26. National Spinal Cord Injury Statistical Center. 2016 spinal cord injury facts and figures at a glance. University of Alabama at Birmingham. www.nscisc.uab.edu. Accessed 16 Dec 2017.

27. Samson G, Cardenas DD. Neurogenic bladder in spinal cord injury. Phys Med Rehabil Clin N Am. 2007;18:255-74. viS10479651(07)00025-3

28. Weld KJ, Graney MJ, Dmochowski RR. Differences in bladder compliance with time and associations of bladder management with compliance in spinal cord injured patients. J Urol. 2000;163:1228-33. S0022-5347(05)67730-0

29. Chen Y, DeVivo MJ, Roseman JM. Current trend and risk factors for kidney stones in persons with spinal cord injury: a longitudinal study. Spinal Cord. 2000;38:346-53.

30. Thietje R, Pouw MH, Schulz AP, Kienast B, Hirschfeld S. Mortality in patients with traumatic spinal cord injury: descriptive analysis of 62 deceased subjects. J Spinal Cord Med. 2011;34:482-7. https:// doi.org/10.1179/2045772311Y.0000000022

31. DeVivo MJ, Stover SL. Long term survival and causes of death. In: Stover SL, DeLisa JA, Whiteneck GG, editors. Spinal cord injury: clinical outcomes from the model systems. Gaithersburg: Aspen; 1995. p. 298-316.

32. Biering-Sorensen F, Kennelly M, Kessler TM. et al. International spinal cord injury lower urinary tract function basic data set (version 2.0). Spinal Cord Ser Cases. 2018;4:60-018-0090-7. eCollection 2018. https://doi.org/10.1038/s41394-018-0090-7.

33. Alexander MS, Biering-Sorensen F, Bodner D, et al. International standards to document remaining autonomic function after spinal cord injury. Spinal Cord. 2009;47:36-43. https://doi.org/10.1038/ sc. 2008.121 